\title{
A density functional theory study of atomic oxygen and nitrogen adsorption over $\alpha$-alumina (0001)
}

\author{
P. Gamallo and R. Sayós * \\ Departament de Química Física i Centre de Recerca en Química Teòrica, \\ Universitat de Barcelona, C. Martí i Franquès 1, 08028 Barcelona (Spain)
}

\begin{abstract}
:
The interaction of atomic oxygen and nitrogen on the (0001) surface of corundum $(\alpha-$ alumina) is investigated from first-principles by means of periodic density functional calculations within the generalized gradient approximation. A large $\mathrm{Al}_{2} \mathrm{O}_{3}$ slab model (18 layers relaxing 10) ended with the most stable aluminum layer is used throughout the study. Geometries, adsorption energies and vibrational frequencies are calculated for several stationary points for two spin states at differents sites over an 1x1 unit cell. Two stable adsorption minima over $\mathrm{Al}$ or in a bridge between $\mathrm{Al}$ and $\mathrm{O}$ surface atoms are found for oxygen and nitrogen, without activation energies. The oxygen adsorption (e.g., $\mathrm{E}_{\mathrm{ad}}=2.30 \mathrm{eV}$ ) seems to be much more important than for nitrogen (e.g., $\mathrm{E}_{\mathrm{ad}}=1.23 \mathrm{eV}$ ). Transition states for oxygen surface diffusion are characterized and present not very high-energy barriers. The computed geometries and adsorption energies are consistent with similar adsorption theoretical studies and related experimental data for $\mathrm{O}, \mathrm{N}$ or $\alpha$-alumina. The present results along with our previous results for $\beta$-cristobalite do not support the assumption of an equal $\mathrm{E}_{\mathrm{ad}}$ for $\mathrm{O}$ and $\mathrm{N}$ over similar oxides, which is commonly used in some kinetic models to derive catalytic atomic recombination coefficients for atomic oxygen and nitrogen. The magnitude of $\mathrm{O}$ and $\mathrm{N}$ adsorption energies imply that Eley-Rideal and Langmuir-Hinshelwood reactions with these species will be exothermic, contrary to what happens for $\beta$-cristobalite.
\end{abstract}

Keywords: Adsorption, alumina, atomic oxygen, atomic nitrogen, minima, diffusion, transition state, density functional theory, exothermic, corundum

Tables: $\quad 4$

Figures: 5

Proofs to: Dr. R. Sayós

* Author for correspondence: e-mail: r.sayos@ub.edu 


\section{Introduction}

Aluminum oxide $\left(\mathrm{Al}_{2} \mathrm{O}_{3}\right)$, traditionally referred to as alumina, is a very important ceramic material of enormous technological importance with a wide range of applications, from electronics, optics, biomedical and mechanical engineering to catalyst support. Its high applicability is due to its enormous hardness (9 Mohs), extreme melting point (2327 $\pm 6 \mathrm{~K})$ and excellent thermal (30 $\mathrm{W} \cdot \mathrm{m}^{-1} \cdot \mathrm{K}^{-1}$ at $\left.373 \mathrm{~K}\right)$ and electrical $\left(>10^{-12} \mathrm{ohm}^{-1} \bullet \mathrm{m}^{-1}\right)$ insulator behaviour ${ }^{1}$. In its crystalline form, called corundum, its hardness makes it suitable for use as an abrasive and as a component in cutting tools. Synthetic corundum is usually produced by the flame-fusion method (also called Verneuil process), allowing the production of large quantities of sapphire, rubies and other corundum gems.

The oxygen atoms in corundum are arranged in a hexagonal close-packed array, with the smaller aluminium atoms occupying two-thirds of the octahedral holes, leading to a crystal belonging to the space group with 30 atoms $\left(6 \mathrm{Al}_{2} \mathrm{O}_{3}\right.$ units $)$ per primitive unit cell. The structure of $\alpha-\mathrm{Al}_{2} \mathrm{O}_{3}(0001)$ surface has been subject of a large amount of studies due to the disparity of the theoretical results ${ }^{2-6}$, also in comparison with experimental data ${ }^{7-8}$, which present problems related with the preparation of clean and well-ordered surfaces in ultrahigh vacuum.

There have been published a lot of density functional theory (DFT) studies about the adsorption of metals (e.g., $\mathrm{Co}$ and $\mathrm{Ni}{ }^{9}, \mathrm{Cu}, \mathrm{Ag}$, and $\mathrm{Au}{ }^{10-11}, .$. ) or molecules (e.g., $\mathrm{H}_{2} \mathrm{O}{ }^{12}$, nitromethane $\left.{ }^{13}, ..\right)$ over $\alpha$-alumina but to our knowledge there are not studies about the adsorption of atomic or molecular oxygen and nitrogen. Moreover, recent experimental studies ${ }^{14-15}$ have determined the catalytic atomic recombination coefficient for oxygen $\left(\gamma_{0}\right)$ over sintered alumina at high temperatures (900-2400K) for $200 \mathrm{~Pa}$ of total air pressure. These experiments try to give new data about the behaviour of new materials that could be used in the design of thermal protection systems (TPS) to be used in space vehicles during their re-entries into the Earth's atmosphere. TPSs must have a low catalytic efficiency to reduce the surface heat flux due to atomic ( $\mathrm{O}$ and $\mathrm{N}$ ) recombination processes. Alumina properties seem to be suitable to use this oxide into the composition of new TPSs. The kinetic models regarding these heterogeneous reactions ${ }^{16}$ should include at least the atomic adsorption/desorption processes and the Eley-Rideal (ER) and Langmuir-Hinshelwood (LH) atomic recombinations. Therefore, the first step in this theoretical approach will be the study of $\mathrm{O}$ and $\mathrm{N}$ adsorption over $\alpha-\mathrm{Al}_{2} \mathrm{O}_{3}(0001)$ surface in a similar way as we have recently carried out for $\beta$-cristobalite ${ }^{17}$, which is another oxide used in several TPSs ${ }^{16}$.

The central aim of our research in progress is the full theoretical study from first-principles of $\mathrm{O}$ and $\mathrm{N}$ recombination reactions over $\alpha$-alumina (i.e., $\mathrm{O}+\mathrm{O}_{\mathrm{ad}}, \mathrm{N}+\mathrm{N}_{\mathrm{ad}}, \mathrm{O}+\mathrm{N}_{\mathrm{ad}}$ or $\mathrm{N}+\mathrm{O}_{\mathrm{ad}}$ ) in 
order to provide not only DFT information on the ground potential energy surfaces but also kinetic and dynamical data useful for next computational fluid dynamics (CFD) simulations about spacecraft flights. The present study will allow ascertaining the relative importance of $\mathrm{O}$ and $\mathrm{N}$ adsorption and also the magnitude of the unknown exothermicities (or endothermicities) for the different ER and LH processes involving these atomic species.

In the present work we have carried out DFT calculations for the $\mathrm{O}$ and $\mathrm{N}$ adsorption over $\alpha-$ alumina (0001) with an Al-terminated first layer because this surface is the most stable according to experimental results ${ }^{8}$ obtained by low-energy electron diffraction over different ended samples. This information and some additional DFT calculations will be used in a following construction of an analytical potential energy surface for dynamical studies about atomic sticking and also for some ER or LH reactions involving $\mathrm{O}$ and $\mathrm{N}$ atoms.

\section{Computational details}

We have performed DFT calculations using the VASP code ${ }^{18-21}$, based on plane wave basis sets. The calculations reported here have been performed at the spin-polarized generalized gradient correction (GGA) level of density functional theory, using the Perdew-Wang 91 functional (PW91) 22-23, which has been appropriate in similar studies $6,13,17$. The electron-ion interactions were described by using the projector-augmented-wave (PAW) technique ${ }^{24-25}$, particularly reliable for transition metals and oxides. We have also checked widely the correct energy cut-off (i.e., $500 \mathrm{eV}$ ) in several bulk and slab calculations.

Integration over the Brillouin zone was performed by using several k-points meshes to ensure the totally convergence in the results. Geometrical optimizations and vibrational frequencies were computed with an energy accuracy of $10^{-6} \mathrm{eV}$.

In the adsorption studies we have used an $1 \times 1$ surface unit cell for the $\alpha$-alumina (0001); 18 layers with an $\mathrm{Al}$ outermost layer formed the final slab model. Thus, to ensure the bulk behaviour, the last eight layers were kept fixed while the others were fully relaxed. The thickness between slabs $(\approx 14 \AA)$ was large enough to prevent significant interactions between them.

Several adsorption sites were characterized for both $\mathrm{O}$ and $\mathrm{N}$ adatoms. Spin magnetic moments were checked along with the corresponding analysis of $\alpha$ and $\beta$ density of of states (DOS) in order to classify the structures as singlet, triplet, doublet or quartet.

Once determined the optimal geometry (without any symmetry restriccion) for each adsorption site, we calculated the Hessian matrix and its corresponding harmonic vibrational 
frequencies $\left(v_{i}\right)$ for the adatom. These can be approximately classified as two parallel and one perpendicular movement, keeping fixed the optimized slab geometry. The adsorption energy $\left(\mathrm{E}_{\mathrm{ad}}\right)$ was defined as $\mathrm{E}_{\mathrm{ad}}=\mathrm{E}($ atom $)+\mathrm{E}(\mathrm{slab})-\mathrm{E}($ atom+slab), where $\mathrm{E}($ atom $)$ is the total calculated ground state energy of the atom in gas phase (i.e., $\left.\mathrm{O}\left({ }^{3} \mathrm{P}\right), \mathrm{N}\left({ }^{4} \mathrm{~S}\right)\right), \mathrm{E}(\mathrm{slab})$ is the energy for the relaxed clean slab in its singlet state and $\mathrm{E}(\mathrm{atom}+\mathrm{slab})$ is the energy of the partial relaxed slab containing the adatom. Thus, a positive adsorption energy for a particular site means that this stationary point is a minimum; on the contrary, a negative adsorption energy corresponds to another stationary point (usually a transition state) less stable than the atom + slab asymptote.

$\mathrm{O}$ and $\mathrm{N}$ atomic energies were calculated with the atom inside large broken symmetry boxes (i.e., $8 \times 7.5 \times 7.6 \AA^{3}$ ). The well known DFT energy uncertainties (approximately $0.1-0.2 \mathrm{eV}$ ) ${ }^{26}$ for atomic degenerate ground states (e.g., B, $\mathrm{N}$ or $\mathrm{O}$ atoms) should be considered not so relevant in this context where large enough adsorption energies are obtained. On the other hand, it is expected that these uncertainties will be lower or similar to the differences in $E_{a d}$ that can be derived by using other functionals, as this has been established in similar studies $\left(\Delta \mathrm{E}_{\mathrm{ad}} \leq 0.5 \mathrm{eV}^{27}\right)$.

\section{Results and discussion}

\subsection{Bulk and slab calculations for the $\alpha$-alumina}

A primitive rombohedral unit cell can be used to describe $\alpha$-alumina, with two $\mathrm{Al}_{2} \mathrm{O}_{3}$ formula units ( space group). Nevertheless, more convenient is the hexagonal unit cell that contains 12 $\mathrm{Al}$ atoms and $18 \mathrm{O}$ atoms (i.e., $6 \mathrm{Al}_{2} \mathrm{O}_{3}$ units). The hexagonal cell corresponds to a layered structure with six oxygen planes associated with aluminum planes above and below it, forming stochiometric triple layers (Fig. 1a). There are three $\mathrm{O}$ atoms and just one $\mathrm{Al}$ atom in each layer (Fig. 1b) per unit cell (Al-3O-Al-Al-3O-Al-Al-3O-Al-Al-3O-Al-Al-3O-Al-Al-3O-Al). The O atoms are stacked in a slightly distorted hcp structure. Three $\mathrm{O}$ atoms forming a triangle in the upper and also in the lower plane round each aluminum atom layer (Fig. 2a), and this spatial conformation draws a hexagonal figure in the top view.

Although $\mathrm{Al}_{2} \mathrm{O}_{3}$ crystallizes in a rather complex bulk structure, at room temperature no reconstructions are observed. Calculated surface energies as a function of the oxygen chemical potential for different $1 \times 1$ terminations show that over the entire range of oxygen chemical potentials the stochiometric Al-3O-Al-termination is by far the energetically most favourable one. This can be understood by simple electrostatic arguments due to the triple $\mathrm{Al}-3 \mathrm{O}-\mathrm{Al}$ slab does not 
have a dipole moment while all other $1 \mathrm{x} 1$ surface terminations have one. Nevertheless, to check this, we have carried out a brief DFT study to obtain a good energetic disposal of the Al termination using both the $\mathrm{Al}-3 \mathrm{O}-\mathrm{Al}$ and the $\mathrm{Al}-\mathrm{Al}-3 \mathrm{O}$ termination obtaining that the $\mathrm{Al}-3 \mathrm{O}-\mathrm{Al}$ termination is about $8.00 \mathrm{eV}$ more stable than $\mathrm{Al}-\mathrm{Al}-3 \mathrm{O}$ termination.

First of all, to obtain the optimal cell parameters, a complete optimization has been performed, including the minimization of both the force acting over each atom and the stress tensor allowing volume and shape relaxation. The optimal cell parameters $(\mathrm{a}=\mathrm{b}$ and $\mathrm{c})$ along with the two types of $\mathrm{AlO}$ distances and <OAlO angles (Fig. 1a) of the inner bulk structure are reported in Table 1 and compared with experimental data ${ }^{28}$. The agreement is quite good.

The slab model used consists of 18 layers; the first 10 were relaxed and the last 8 kept fixed to ensure the bulk behaviour. An interlayer relaxation (i.e., $\Delta \mathrm{d}_{12}, \Delta \mathrm{d}_{23}, \ldots$ ) analysis is showed in Table 2. The most significant feature is the high inward relaxation of the surface plane (approx. -90 $\%$ ) together with a smaller outward (approx. $+4 \%$ ), large inward (approx. $-46 \%$ ) and large outward (approx. 20\%) relaxations of the second, third and fourth layers, respectively. The results obtained in this work agree well with previous theoretical 19,23 data and reproduce at least qualitatively the experimental ${ }^{7-8}$ results, although an excellent agreement is found for $\mathrm{Al}_{(3)}-\mathrm{O}_{(2)}$ relaxation. Nevertheless, the first aluminum layer inward relaxation is overestimated. The high relaxation of the first aluminum layer makes that this becomes almost coplanar with the first oxygen layer (Fig. 2b) with an $\mathrm{AlO}_{3}$ electronically deficient coordination. Thus, a reduction in $\mathrm{AlO}$ distances (i.e., $\mathrm{d}\left(\mathrm{Al}_{(1)}-\mathrm{O}_{(1)}\right)=1.704 \AA$ ) is produced when compared with bulk distances (Table 1) whereas much bigger $<\mathrm{OAlO}$ angles are achieved (i.e., $<\mathrm{O}_{(1)} \mathrm{Al}_{(1)} \mathrm{O}_{(1)}=119.7^{\circ}$ ). This trend in distances when lowering coordination agree with experimental gas-phase AlO distances in linear $\mathrm{AlO}_{2}(\mathrm{~d}(\mathrm{Al}-\mathrm{O})=1.69 \AA)$ or $\mathrm{AlO}$ molecules $(\mathrm{d}(\mathrm{Al}-\mathrm{O})=1.62 \AA)^{29}$. Two explanations for this big relaxation have been expressed previously ${ }^{2-3}$; the first one is based on the rehybridization of the surface $\mathrm{Al}$ atom to an $\mathrm{sp}^{2}$ orbital configuration, which favours the planar structure (bigger angles and long distances); the second one rely on the reduction of the ionicity ${ }^{30}$ of the surface relative to the bulk due to the outer $\mathrm{Al}^{3+}$ ion becomes strongly coordinated to the first layer $\mathrm{O}^{2-}$ ions to counteract the excess of positive charge.

Some authors have also remarked that this disagreement between experimental and theoretical first aluminum relaxation could be originated by the unfeasibility to obtain a real aluminum ended clean surface even at ultrahigh vacuum. It has been shown that an $\alpha-\mathrm{Al}_{2} \mathrm{O}_{3}$ (0001) surface in equilibrium with an environment containing both oxygen and hydrogen species is fundamental for obtaining theoretical predictions consistent with experimental information ${ }^{4}$. 
On the other hand, the Fermi energy obtained for the bulk model was $6.4 \mathrm{eV}$, which is lower than the experimental value of $8.7 \mathrm{eV}^{31}$ but much closer than another previous theoretical values (e.g., $\left.5.8 \mathrm{eV}^{32}\right)$.

\subsection{Atomic oxygen adsorption on $\alpha$-alumina}

We have studied the adsorption of atomic oxygen on four different sites over the unit cell of $\alpha-\mathrm{Al}_{2} \mathrm{O}_{3}$ (0001) (Fig. 1b) for the lowest singlet and triplet spin states. Thus, two top sites have been considered, one over an atom of the $\mathrm{Al}_{(1)}$ layer ( $\mathrm{T} 1$ site) and another over an atom of the $\mathrm{O}_{(1)}$ layer (T2 site). The third site is a bridge (B) between an oxygen and an aluminum of $\mathrm{O}_{(1)}$ and $\mathrm{Al}_{(1)}$ layers. This bridge site is available because of the coplanarity of first aluminum and oxygen layers achieved after the mentioned surface relaxation. The fourth site is a hollow $(\mathrm{H})$ in which the adatom coordinates three oxygens of the $\mathrm{O}_{(1)}$ layer, located as well along the vertical line that contains a deeper oxygen of the $\mathrm{O}_{(2)}$ layer.

Table 3 summarizes the results for these four sites. Two different behaviours are obtained for singlet and triplet states. In the case of singlet state, the most stable adsorption is found in T2 site (2.30 eV of adsorption energy) whereas the adsorption in T1 and B sites is quite similar (around $1.50 \mathrm{eV}$ ). In the case of the triplet state, the most stable site is observed in T1 site, with an adsorption energy of $1.82 \mathrm{eV}$; in all other sites the adsorption energy in the triplet state is lower than $0.80 \mathrm{eV}$. Hollow site is in both cases only slightly stable.

The $\mathrm{O}_{\mathrm{ad}} \mathrm{A} 1$ distances in $\mathrm{T} 1$ and $\mathrm{T} 2$ minima (Table 3 ) are approximately $0.1-0.2 \AA$ lower to the bulk $\alpha$-alumina values (experimental values between 1.855-1.972 $\AA$, shown in Table 1) or to the AlO lengths reported in DFT calculations on the adsorption of nitromethane (1.906-1.942 $\AA$ ) over $\alpha-\mathrm{Al}_{2} \mathrm{O}_{3}(0001)^{13}$, where the binding takes place mainly through the formation of a bond between one oxygen of the nitro group to an $\mathrm{Al}$ of the surface. Nevertheless, our calculated distances are still larger than the corresponding value in the gas-phase diatomic molecule (i.e., $1.6179 \AA$ in ground ${ }^{2} \Sigma^{+}$state $\left.{ }^{1}\right)$, which presents a much higher bond dissociation energy $(\mathrm{BDE}=5.2 \pm 0.1 \mathrm{eV}$ at $298 \mathrm{~K}^{1}$ ). This fact is coherent with the lower BDEs obtained for both adsorption minima. Thus, in $\mathrm{T} 1$ the $\mathrm{BDE}\left(\right.$ at $0 \mathrm{~K}$ ) corresponds approximately to the calculated $\mathrm{E}_{\mathrm{ad}}$ as only one $\mathrm{AlO}$ bond is formed (Fig. 2c). This energy is close to the DFT binding energies (i.e., 0.83-1.13 eV) obtained for nitromethane on $\alpha-\mathrm{Al}_{2} \mathrm{O}_{3}(0001)$ with mostly $\mathrm{AlO}$ bonding ${ }^{13}$.

In $\mathrm{T} 2$ minimum, the existence of two bonds (i.e., AlO and OO, Fig. 2d), as the distances to another $\mathrm{O}$ or $\mathrm{Al}$ are too high, implies that both BDEs will be even lower. In fact, as $\mathrm{AlO}$ and $\mathrm{O}_{2}$ 
gas-phase molecules present similar $\mathrm{BDE}\left(\mathrm{BDE}=5.165 \pm 0.001 \mathrm{eV}\right.$ at $298 \mathrm{~K}$ for $\mathrm{O}_{2}\left(\mathrm{X}^{3} \Sigma_{\mathrm{g}}\right)^{1}$ to be compared with the AlO value before mentioned), a first estimate to both BDE could be equal to $\mathrm{E}_{\mathrm{ad}} / 2$ value (i.e., $1.15 \mathrm{eV}$ for $\mathrm{T} 2$ singlet state). Moreover, the $\mathrm{O}_{\mathrm{ad}} \mathrm{O}$ distance in $\mathrm{T} 2(1.55 \AA)$ is also higher than the $\mathrm{OO}$ distance in the gas-phase diatomic molecule (i.e., $1.2075 \AA$ in ground ${ }^{3} \Sigma_{\mathrm{g}}{ }^{-}$state 1 ), in agreement with a less stable structure. This type of three-membered peroxy structure is similar to dioxasilyrane group $=\mathrm{Si}\left(\mathrm{O}_{2}\right)$, proposed to assign the observed optical transitions in the surface of activated silica ${ }^{34-35}$, with ab initio calculated OO distances within the interval 1.538$1.656 \AA$, being also the singlet the most stable state.

Despite the absence of experimental adsorption energies for atomic oxygen over alumina, the comparison with another oxides shows smaller adsorption energies (e.g., 2.0-2.5 eV on $\mathrm{MgO}(001)$ 33 or 3.7-5.9 eV on $\mathrm{SiO}_{2}(100){ }^{17}$ ), although closer to $\mathrm{MgO}$ values, possibly because alumina is also an ionic oxide.

To analyze the electronic properties of both minima (T1 and T2), partial density of states projected onto the oxygen and aluminum atoms involved mainly in the bonds are presented for T1 in Fig. 3 and for T2 in Fig. 4, for both spin states. In T1 triplet, the $3 p_{z}$ states of $\mathrm{Al}_{(1)}$ in $\mathrm{Al}_{2} \mathrm{O}_{3} \mathrm{slab}$, located at the beginning of the conduction band (approx. $4 \rightarrow 5 \mathrm{eV}$ ), are moved to the valence band (approx. $-1 \rightarrow-4 \mathrm{eV}$ in Fig. 3) due to the new $\mathrm{AlO}$ bond, with possibly less ionic character in comparison with an $\mathrm{AlO}$ bond inside the slab. There is as well a significant overlapping of $\mathrm{O}_{\mathrm{ad}} 2 \mathrm{p}_{\mathrm{x}, \mathrm{y}}$ and $\mathrm{Al}_{(1)} 3 \mathrm{p}_{\mathrm{x}, \mathrm{y}}$ states, strengthening this bond. For $\mathrm{T} 1$ singlet this latter overlapping is a bit minor, which is consistent with its lower binding energy (or $E_{a d}$ ).

In T2 singlet minimum the $\mathrm{O}_{\mathrm{ad}} 2 \mathrm{p}_{\mathrm{x}, \mathrm{y}}$ states and $\mathrm{Al}_{(1)} 3 \mathrm{p}_{\mathrm{x}, \mathrm{y}, \mathrm{z}}$ states participate principally in the AlO (bond) valence band, while $\mathrm{O}_{\mathrm{ad}} 2 \mathrm{p}_{\mathrm{z}}$ is moved to approximately $1 \mathrm{eV}$, with a less participation in agreement with the geometry obtained (Fig. 2d), which favoured more this kind of orbitalic overlapping. The major contribution into the less strong peroxo bond (1.554 $\AA$ of bond distance, Table 3 ) formed by $\mathrm{O}_{\mathrm{ad}}$ and $\mathrm{O}_{(1)}$ seems to be given mostly by $2 \mathrm{p}_{\mathrm{x}, \mathrm{y}}$ states of both oxygens, as their $2 \mathrm{p}_{\mathrm{z}}$ states are separated each other around $1.5 \mathrm{eV}$ (Fig. 4). For T2 triplet minimum it is observed a stronger overlapping of $\mathrm{Al}_{(1)}$ and $\mathrm{O}_{(1)} \mathrm{p}_{z}$ states (with more population of the $\alpha$ spin states in both atoms) at $-15 \mathrm{eV}$ giving place to a strong $\mathrm{O}_{(1)} \mathrm{Al}_{(1)}$ bond and therefore, the other $\mathrm{O}_{\text {ad }} \mathrm{Al}_{(1)}$ bond should be weakened, producing a much less binding energy and $E_{a d}$ as observed (Table 3).

$\mathrm{T} 1$ and T2 structures are truly minima as we have verified by the analysis of harmonic vibrational frequencies (Table 3). In the case of adsorption of oxygen atom on $\mathrm{T} 1$ site, it is observed that the perpendicular frequency is much higher than the two parallel ones, and it is easy to understand this value according to the $\mathrm{T} 1$ minimum geometry; in $\mathrm{T} 1$ minimum, the distance 
between the $\mathrm{O}$ adatom and the first aluminum is practically the bulk distance (see Table 1) but differs from bulk structure in the location of neighbouring atoms; that is, in the bulk structure each aluminum atom is located in an octahedral hole coordinated to $6 \mathrm{O}$ atoms (Fig. 2a) but in T1 the coordination is only four (Fig. 2c), with an $\mathrm{Al}$ and three $\mathrm{O}$ in almost the same plane. Therefore, the perpendicular frequency corresponds mainly to the $\mathrm{O}_{\mathrm{ad}} \mathrm{Al}$ stretching with a high value $\left(541.3 \mathrm{~cm}^{-1}\right.$ and $510.9 \mathrm{~cm}^{-1}$ for singlet and triplet states, respectively) because this is a strong bond whereas the parallel movements along the $\mathrm{T} 1-\mathrm{T} 2$ and $\mathrm{T} 1-\mathrm{H}$ lines have less frequencies due to the interactions with neighbour atoms in the same or in the deeper layers are clearly less important.

The AlO stretching frequencies in $\mathrm{T} 1$ minimum are in the range $500-550 \mathrm{~cm}^{-1}$, which is much closer to the experimental frequencies ${ }^{36}$ associated to condensed $\mathrm{AlO}_{6}$ octahedra (i.e., $500-680 \mathrm{~cm}^{-}$ $\left.{ }^{1}\right)$ than to the frequencies for condensed $\mathrm{AlO}_{4}$ tetrahedra (i.e., 700-900 $\mathrm{cm}^{-1}$ ) or to the AlO gasphase diatomic molecule (i.e., $979 \mathrm{~cm}^{-1} 1$ ). In fact, corundum, which is built up by $\mathrm{AlO}_{6}$ octahedra only, presents two strong IR bands near 600 and $650 \mathrm{~cm}^{-136}$.

T2 structure, the most stable minimum, shows higher parallel frequencies than T1 minimum, because $\mathrm{T} 2$ has two short distances (i.e., $\mathrm{O}_{\mathrm{ad}} \mathrm{Al}_{(1)}$ and $\mathrm{O}_{\mathrm{ad}} \mathrm{O}_{(1)}$ ) and a small $\mathrm{z}_{\text {Oad }}$ value, which is shorter than in T1 (e.g., $0.945 \AA$ compared with $1.776 \AA$ in singlet state), which means a stronger interaction for parallel movements to the surface (e.g., in the $\mathrm{O}_{\mathrm{ad}}-\mathrm{Al}_{(1)}$ direction).

B site is in between T1 and T2 minima. According to their vibrational frequencies (Table 3) it is a diffusion transition state in both spin states, connecting T1 and T2 minima in $y$ direction (Fig. 1b). However, there is a great difference between singlet and triplet $\mathrm{B}^{\neq}$structures; the $\mathrm{B}^{\neq}$singlet is closer to $\mathrm{T} 1$ minimum and there is a low energy barrier (i.e., $0.06 \mathrm{eV}$ for $\mathrm{T} 1 \rightarrow \mathrm{B}^{\neq} \rightarrow \mathrm{T} 2$ ), corresponding to an exothermic diffusion path (Fig. 5). On the contrary, the $\mathrm{B}^{\neq}$triplet structure is much closer to T2 minimum and now the diffusion process is endothermic, being the energy barrier somewhat higher than the endothermicity (i.e., $1.07 \mathrm{eV}$ for $\mathrm{T} 1 \rightarrow \mathrm{B}^{\neq} \rightarrow \mathrm{T} 2$ ) (Fig. 5). In the case of $\mathrm{B}^{\neq}$triplet the imaginary frequency corresponds to a perpendicular movement to the surface (i.e., $551.9 \mathrm{i} \mathrm{cm}^{-1}$ ), whereas in the case of $\mathrm{B}^{\neq}$singlet it is parallel to the surface (i.e., $58.1 \mathrm{i} \mathrm{cm} \mathrm{cm}^{-1}$ ) and its value is clearly minor. This is consistent with the geometrical changes involved in both T1 $\rightarrow$ T2 diffusion paths. Thus, in triplet state it involves mainly a big reduction of one $\mathrm{O}_{\mathrm{ad}} \mathrm{O}_{(1)}$ distance from 2.872 to $1.700 \AA$ (or $\mathrm{z}_{\text {Oad }}$ changes from 1.799 to $1.054 \AA$ ) to achieve the transition state. The other two $\mathrm{O}_{\mathrm{ad}} \mathrm{O}_{(1)}$ distances increase only a bit. The final pass from $\mathrm{B}^{\neq}$to $\mathrm{T} 2$ is produced by reducing even more the $\mathrm{O}_{\mathrm{ad}} \mathrm{O}_{(1)}$ distance to $1.552 \AA$, but with practically no change in the energy. In the case of $\mathrm{B}^{\neq}$singlet, the path needs a much less $\mathrm{O}_{\mathrm{ad}} \mathrm{O}_{(1)}$ distance reduction from 2.910 to $2.458 \AA$ ( $\mathrm{z}_{\text {Oad }}$ changes only from 1.776 to $1.615 \AA$ ) and only a small parallel movement to the surface is needed 
to achieve this transition state. After that, a significant $\mathrm{O}_{\mathrm{ad}} \mathrm{O}_{(1)}$ distance decrease until $1.554 \AA$ is necessary to achieve the T2 minimum.

Hollow site is another transition state $\left(\mathrm{H}^{\ddagger}\right)$ that connects also T1 and T2 but in the $x$ direction (Fig. 1b). Now the energetics for $\mathrm{T} 1 \rightarrow \mathrm{H}^{\ddagger} \rightarrow \mathrm{T} 2$ diffusion is similar for both singlet and triplet states (Fig. 5), although there are several discrepancies respect the geometrical changes. In the triplet case, the distance between the oxygen adatom and the first aluminum atom is $1 \AA$ higher (Table 3) than in the singlet state; thus the $\mathrm{O}_{a d} \mathrm{Al}_{(1)}$ interaction is much weaker in the triplet state and drives to obtain one stretching frequency that is a half of the obtained for the singlet state.

$\mathrm{T} 1 \rightarrow \mathrm{H}^{\ddagger} \rightarrow \mathrm{T} 2$ path is endothermic for triplet state and exothermic for singlet state as it occurred for the alternative $\mathrm{T} 1 \rightarrow \mathrm{B}^{\neq} \rightarrow \mathrm{T} 2$ path. Nevertheless, now the energy barriers are higher (i.e., $1.02 \mathrm{eV}$ for singlet and $1.32 \mathrm{eV}$ for triplet).

The information summarized in Fig. 5 could be interpreted as follows. When an oxygen atom collides with a $\alpha-\mathrm{Al}_{2} \mathrm{O}_{3}$ (0001) surface it will be adsorbed (without any activation energy) mainly over an $\mathrm{Al}$ ( $\mathrm{T} 1$ site) or one of the three equivalent oxygens $\left(\mathrm{O}_{1 \mathrm{a}}, \mathrm{O}_{1 \mathrm{~b}}, \mathrm{O}_{1 \mathrm{c}}\right)$ of $\mathrm{O}_{(1)}$ layer $(\mathrm{T} 2$ sites $)$. If it is initially adsorbed in T1 site, there will be two possibilities to migrate to the most stable T2 singlet minimum, being the path $\mathrm{T} 1 \rightarrow \mathrm{B}^{\neq} \rightarrow \mathrm{T} 2$ the energetically most favourable. Nevertheless, it could be expected that both paths will be accessible at low atomic kinetic energies and moderate surface temperatures. On the other hand, the initial adsorption over one of the three equivalent T2 sites will be statistically more probable and will lead to the most stable singlet minima. The change from the initial atomic triplet state (arising from $\mathrm{O}\left({ }^{3} \mathrm{P}\right)$ ) to the final $\mathrm{T} 2$ singlet state can be progressively produced when approaching the $\mathrm{O}$ atom to the surface. In fact, DFT calculations show no energy barrier to produce directly $\mathrm{T} 1$ and $\mathrm{T} 2$ minima when $\mathrm{O}\left({ }^{3} \mathrm{P}\right)$ becomes closer to these sites.

The diffusive processes of oxygen over $\alpha-\mathrm{Al}_{2} \mathrm{O}_{3}$ (0001) surface are not too energetically demanding in opposite to what happens when oxygen atoms are adsorbed on another oxide as $\beta$ cristobalite (100). In this latter case, we found strong diffusion energy barriers within the 3.0-6.6 interval ${ }^{17}$.

\subsection{Nitrogen adsorption on $\alpha$-alumina}

In spite of the most relevant importance of oxygen interaction with the TPSs of spacecrafts due to its lower molecular energy dissociation and the main abundance of its molecular species in air in comparison to molecular nitrogen, we have also characterized the adsorption minima of 
nitrogen atoms over $\mathrm{T} 1$ and $\mathrm{T} 2$ sites for doublet and quartet states because this information is relevant for the study of the ER reactions that could be necessary in more acurate air kinetic simulations. Both, energetics and geometries are given in Table 4.

The $\mathrm{N}_{\mathrm{ad}} \mathrm{Al}$ distance in $\mathrm{T} 2$ doublet adsorption minimum (Table 4) is similar as for typical AlN bonds in solid state. Thus, in the hexagonal equilibrium wurtzite form of aluminum nitride (unit cell with $\mathrm{a}=3.111 \AA, \mathrm{c}=4.978 \AA$ and $\mathrm{u}=0.385$, belonging to $\mathrm{P}_{3} \mathrm{mc}$ space group ${ }^{37}$ ), each $\mathrm{Al}$ is tetrahedrically coordinated by four $\mathrm{N}$ atoms (and vice versa), but presents three equivalent distances of $1.885 \AA$ and one of $1.917 \AA$. In the metastable-phase of aluminum nitride with a cubic zincblende structure (unit cell with $\mathrm{a}=4.38 \AA$, belonging to $\quad$ space group ${ }^{38}$ ) the four distances are equal to $1.897 \AA$. These distances are somewhat higher than the AlN calculated distances reported for several AlN nanotubes (i.e., 1.82-1.83 $\AA^{39-40}$ ), for the adsorption of some $\mathrm{N}$ hydrides over Al (0001) face of the wurtzite form of aluminum nitride (i.e., $1.788 \AA^{41}$ ) or for the experimental distance in gas-phase diatomic molecule (i.e., $1.7864 \AA$ for $\mathrm{AlN}\left(\mathrm{X}^{3} \Pi^{42}\right)$.

The $\mathrm{N}_{\mathrm{ad}} \mathrm{O}$ distance in $\mathrm{T} 2$ doublet adsorption minimum (Table 4) is much higher than the corresponding value for the gas-phase diatomic molecule (i.e., $1.1508 \AA$ for $\mathrm{NO}\left(\mathrm{X}^{2} \Pi_{1 / 2}{ }^{1}\right)$. Nevertheless, this behaviour is quite similar to the one observed in the study of the $\mathrm{N}$ adsorption over the $\mathrm{O}$ face of $\beta$-cristobalite (100) for a bridge with two $\mathrm{O}$ atoms (i.e., $\mathrm{d}_{\mathrm{NO}}=1.34-1.44 \AA$ in $\mathrm{B} 3$ minimum ${ }^{17}$ ).

Despite the existence of four stationary points, only a relatively stable minimum is found in $\mathrm{T} 2$ site for doublet state (1.23 eV of adsorption energy). A less stable minimum is found in $\mathrm{T} 1$ site for quartet state (only $0.4 \mathrm{eV}$ of adsorption energy). Vibrational frequencies follow a similar behaviour as for oxygen adsorption, already explained in previous section. In this case transition states are not reported for this rather shallow minima, although several searches were unsuccessfully carried out.

The analysis of the two bond distances in T2 minimum points out that AlN bond should be stronger than NO bond in this structure, which has a high BDE of $6.546 \pm 0.002 \mathrm{eV}$ at $298 \mathrm{~K}$ for gas-phase $\mathrm{NO}\left(\mathrm{X}^{2} \Pi_{1 / 2}\right)$ molecule ${ }^{1}$. In spite of the unfeasibility to derive easily BDEs from calculated $E_{a d}$ value, a rough comparison could be done with the calculated AlN binding energies of some $\mathrm{N}$ hydrides over $\mathrm{Al}(0001)$ face of hexagonal aluminum nitride; values of 3.53 and $2.49 \mathrm{eV}$ were reported for $\mathrm{NH}_{2}$ and $\mathrm{NH}$ species at $\mathrm{HF} / 6-31 \mathrm{G}(\mathrm{d})$ level ${ }^{41}$, respectively, whose extrapolation to $\mathrm{N}$ species would be very close to our calculated $\mathrm{E}_{\mathrm{ad}}$ in $\mathrm{T} 2$.

When comparing the $\mathrm{O}$ and $\mathrm{N}$ adsorption results over $\alpha$-alumina, we observe that in both cases the most important adsorption is produced over oxygen atoms of the $\mathrm{O}_{(1)}$ layer (T2 site) at the 
lowest spin multiplicity. The adsorption over aluminum atoms of the $\mathrm{Al}_{(1)}$ layer ( $\mathrm{T} 1$ site) follows the opposite behaviour, with less stable minima and highest spin multiplicity. Thus, it seems that in this highly ionic alumina surface, $\mathrm{Al}^{3+}$ surface cation prefer to make a bond with $\mathrm{O}$ or $\mathrm{N}$ keeping unpaired electrons while $\mathrm{O}^{2-}$ surface anions make stronger bonds with $\mathrm{O}$ or $\mathrm{N}$ atoms pairing the electrons.

The DOS analysis for $\mathrm{N}$ adsorption shows a similar behaviour as for $\mathrm{O}$. Thus, in $\mathrm{T} 1$ structure there is a more important overlapping of $\mathrm{N} 2 \mathrm{p}_{z}$ states with $\mathrm{Al}_{(1)} 3 \mathrm{p}_{z}$ states in quartet (close to -10 $\mathrm{eV}$ ) than in doublet (close to $0 \mathrm{eV}$ ) spin state in agreement with a little most stable $\mathrm{T} 1$ quartet minimum. In T2 minimum, apart from the contribution to the $\mathrm{NAl}$ bonding from $\mathrm{Al}_{(1)} 3 \mathrm{p}_{\mathrm{x}, \mathrm{y}, \mathrm{z}} \mathrm{states}$, the additional overlapping of $2 \mathrm{p}_{\mathrm{x}, \mathrm{y}}$ states arising from $\mathrm{N}_{\mathrm{ad}}$ and $\mathrm{O}_{(1)}$ produce a $\pi \mathrm{NO}$ bonding stronger in the doublet state than in the quartet state, this latter with a clear spin polarization over the $\mathrm{N}$ atom, which gives place to a slightly most stable doublet minimum. A similar behaviour was also observed over $\beta$-cristobalite ${ }^{17}$ and it was explained there more widely.

The collision of nitrogen atom with $\alpha-\mathrm{Al}_{2} \mathrm{O}_{3}$ (0001) surface will be much simpler than for oxygen atoms. Thus, only a significant adsorption minimum (T2) will have some influence on the dynamics of the collision in the case that pairing of two electrons of nitrogen can be achieved during the atomic approaching to the surface. This process will occur without any potential energy barrier.

\section{Summary and conclusions}

In this work we have made a periodic DFT study (GGA/PW91) on the adsorption of atomic oxygen and nitrogen over $\alpha$-alumina (0001) Al-ended surface, considering the two lowest spin states of every system. The adsorption calculations used a slab model with 18 layers, keeping fixed the 8 low-lying layers and allowing the relaxation of the 10 outer-lying ones. Four sites (T1, T2, H, B) over an 1x1 $\alpha$-alumina (0001) unit cell have been investigated.

Two stable adsorption minima over $\mathrm{Al}_{(1)}\left(\mathrm{T} 1\right.$ site) or in a bridge between $\mathrm{Al}_{(1)}$ and $\mathrm{O}_{(1)}$ (T2 site) surface atoms are found for $\mathrm{O}$ and $\mathrm{N}$, without activation energies. The adsorption of $\mathrm{O}$ on $\mathrm{T} 2$ (singlet) is the most stable minimum $\left(\mathrm{E}_{\mathrm{ad}}=2.30 \mathrm{eV}\right)$, where two bonds $(\mathrm{OAl}$ and $\mathrm{OO})$ are formed, while in T1 (triplet) site there is only one OAl bond and consequently it is less stable $\left(\mathrm{E}_{\mathrm{ad}}=1.82\right.$ $\mathrm{eV}$ ). There are rather small energy diffusion barriers between $\mathrm{T} 1$ and T2 minima for both singlet and triplet states, which correspond to the $\mathrm{B}$ and $\mathrm{H}$ structures $\left(\mathrm{T} 1 \rightarrow \mathrm{H}^{\ddagger} \rightarrow \mathrm{T} 2\right.$ or $\mathrm{T} 1 \rightarrow \mathrm{B}^{\neq} \rightarrow \mathrm{T} 2$ paths). Vibrational frequency analysis supports the existence of these transition states. 
The $\mathrm{N}$ adsorption over $\alpha$-alumina on $\mathrm{T} 1$ and $\mathrm{T} 2$ sites is less important. Only a moderately stable minimum is found on T2 (doublet) $\left(\mathrm{E}_{\mathrm{ad}}=1.23 \mathrm{eV}\right)$. In T1 (quartet) a minor (physisorption) is observed $\left(\mathrm{E}_{\mathrm{ad}}=0.40 \mathrm{eV}\right)$.

The geometries, adsorption energies and binding energies for these stationary points can be understood comparing with available similar studies and related experimental data, and also by analysing the density of states. These results together with our previous DFT study for $\beta$-cristobalite do not support the old guess of an equal $\mathrm{E}_{\mathrm{ad}}$ for $\mathrm{O}$ and $\mathrm{N}$ over similar oxides, which has been used in some kinetic models to derive catalytic atomic recombination coefficients for oxygen and nitrogen ${ }^{16}$.

The DFT data obtained suggest that when an oxygen atom collides with an $\alpha-\mathrm{Al}_{2} \mathrm{O}_{3}(0001)$ surface it will be adsorbed mainly over an Al (T1 site) or over one of the three equivalent oxygens $\left(\mathrm{O}_{1 \mathrm{a}}, \mathrm{O}_{1 \mathrm{~b}}, \mathrm{O}_{1 \mathrm{c}}\right)$ of $\mathrm{O}_{(1)}$ layer (T2 sites). A probably fast surface diffusion will take place between both minima even at low atomic kinetic energies and moderate surface temperatures. Nevertheless, a dynamical study (e.g., with classical trajectories) should confirm this fact.

The stronger adsorption found for $\mathrm{O}$ in comparison with $\mathrm{N}$ could enhance more the oxygen Eley-Rideal reaction over $\alpha$-alumina surface at several range temperatures.

The smaller oxygen and nitrogen adsorption energies for $\alpha-\mathrm{Al}_{2} \mathrm{O}_{3}$ than for $\beta$-cristobalite $\left(\mathrm{SiO}_{2}\right)$, means that $\mathrm{O}$ or $\mathrm{N}$ atomic recombination processes via the Eley-Rideal or LangmuirHinshelwood mechanisms (e.g., $\mathrm{O}+\mathrm{O}_{\mathrm{ad}} \rightarrow \mathrm{O}_{2}(\mathrm{~g})$ or $\mathrm{O}_{\mathrm{ad}}+\mathrm{O}_{\mathrm{ad}} \rightarrow \mathrm{O}_{2}(\mathrm{~g})$ ) will be exothermic on $\alpha$ $\mathrm{Al}_{2} \mathrm{O}_{3}$ (i.e., $\Delta \mathrm{E}=-2.90$ or $-0.68 \mathrm{eV}$ for $\mathrm{T} 2 \mathrm{minimum}$, including zero point energies) contrary to the endothermic reactions predicted for $\beta$-cristobalite ${ }^{17}$ (i.e., $\Delta \mathrm{E}=0.86$ or $6.84 \mathrm{eV}$ for $\mathrm{T} 1$ minimum, including zero point energies). Therefore, the major heat reaction than can be transferred to the solid surface along with the greater catalytic activity observed for oxygen over alumina (1000-1700 K) ${ }^{14-15}$ compared with silica (quartz or cristobalite), seem to indicate that $\beta$-cristobalite or silica based materials will be more suitable than $\alpha$-alumina to be used in the construction of new TPSs for spacecrafts. Nevertheless, additional DFT calculations about the ER transition states and dynamical studies analysing the heat transfer to the surface depending on the initial reactant conditions (i.e., atomic collision energy, surface temperature,..) should be made to corroborate definitely this conclusion. 


\section{Acknowledgments}

This work has been supported by the Spanish Ministry of Education and Science (Projects ref. CTQ2006-02195 and UNBA05-33-001) and by the Autonomous Government of Catalonia (Projects ref. 2005SGR00175 and 2005 PEIR 0051/69). The authors are grateful to the Computer Centre of Catalonia (CESCA) for providing a part of the computer time.

\section{References}

1. D. R. Lide (ed.), CRC Handbook of Chemistry and Physics, Internet Version 2007, 87th Edition, <http:/www.hbcpnetbase.com> , Taylor and Francis, Boca Raton, 2007.

2. C. Verdozzi, D.R. Jenniso, P.A. Schultz and M.P. Sears, Phys. Rev. Lett., 1999, 82, 799-802.

3. A. Wander, B. Searle and N.M. Harrison, Surf. Sci., 2000, 458, 25-33.

4. X.-G. Wang, A. Chaka and M. Scheffler, Phys. Rev. Lett., 2000, 84, 3650-3653.

5. J.R.B. Gomes, I. de P.R. Moreira, P. Reinhart, A. Wander, B.G. Searle, N.M. Harrison and F. Illas, Chem. Phys. Lett., 2001, 341, 412-418.

6. J. Carrasco, J.R.B. Gomes and F. Illas, Phys. Rev. B, 2004, 69, 064116-13.

7. P. Guénard, G. Renaud, A. Barbier and M. Gautier-Soyer, Surf. Rev. Lett., 1998, 5, 321-324.

8. E. Soares, M. A. Van Hove, C. F. Walters and K. F. McCarty, Phys. Rev. B, 2002, 65, 195405-13.

9. Q. Ma, K. Klier, H. Cheng, J.W. Mitchell and K.S. Hayes, J. Phys. Chem. B, 2001, 105, 2212-2221.

10. N. Cruz Hernández and J. Fernández Sanz, J. Phys. Chem. B, 2002, 106, 11495-11500.

11. N. Cruz Hernández, J. Graciani, A. Márquez and J. Fernández Sanz, Surf. Sci., 2005, 575, 189-196.

12. K.C. Hass, W.F. Schneider, A. Curioni and W. Andreoni, J. Phys. Chem. B, 2000, 104, $5527-5540$.

13. D.C. Sorescu, J. A. Boatz and D.L. Thompson, J. Phys. Chem. B, 2005, 109, 1451-1463.

14. M.J.H. Balat, M. Czerniak and J.M. Badie, J. Space Rock., 1999, 36, 273-279.

15. M.J.H. Balat-Pichelin, L. Bedra, J.M. Badie and P. Boubert, AIP Conf. Proc., 2005, 762, 941-946.

16. M. Capitelli (ed.), Molecular Physics and Hypersonic Flows, NATO ASI Series C, vol. 482, Kluwer Academic Publishers, Dordrecht, 1996.

17. C. Arasa, P. Gamallo and R. Sayós, J. Phys. Chem. B, 2005, 109, 14954-14964. 
18. G. Kresse and J. Hafner, Phys. Rev. B, 1993, 48, 13115-13118.

19. G. Kresse and J. Hafner, Phys. Rev. B, 1994, 49, 14251-14269.

20. G. Kresse and J. Furthmüller, Comput. Mater. Sci., 1996, 6, 15-50.

21. G. Kresse and J. Furthmüller, Phys. Rev. B, 1996, 54, 11169-11186.

22. J.P. Perdew, J.A. Chevary, S.H. Vosko, K.A. Jackson, M.R. Pederson, D.J. Singh and C. Fiolhais, Phys. Rev. B, 1992, 46, 6671-6687.

23. J.P. Perdew and Y. Wang, Phys. Rev. B, 1992, 45, 13244-13249.

24. P.E. Blöchl, Phys. Rev. B, 1994, 50, 17953-17979.

25. G. Kresse and D. Joubert, Phys. Rev. B, 1999, 59, 1758-1775.

26. E.J. Baerends, V. Branchadell and M. Sodupe, Chem. Phys. Lett., 1997, 265, 481-489.

27. B. Hammer, L.B. Hansen, and J.K. Nørskov, Phys. Rev. B, 1999, 59, 7413-7421.

28. D.E. Gray (ed.), American Institute of Physics Handbook, McGraw-Hill, New York, 1982.

29. M.W. Chase Jr., C.A. Davies, J.R. Downey Jr., D.J. Frurip, R.A. McDonald and A.N. Syverud , J. Phys. Chem. Ref. Data, 1985, 14, suppl. 1.

30. C. Sousa, F. Illas and G. Pacchioni, J. Chem. Phys., 1993, 99, 6818-6823.

31. R.H. French, J. Am. Ceram. Soc., 1990, 73, 477-489.

32. K. Matsunaga, T. Tanaka, T. Yamamoto and Y. Ikuhara, Phys. Rev. B, 2003, 68, 085110-9.

33. L.N. Kantorovich and J.M. Gillan, Surf. Sci., 1997, 374, 373-386.

34. K. Raghavachari and G. Pacchioni, J. Chem. Phys., 2001, 114, 4657-4662.

35. K. Raghavachari, D. Ricci and G. Pacchioni, J. Chem. Phys., 2002, 116, 825-831.

36. P. Tarte, Spect. Acta A, 1967, 23, 2127-2143.

37. R.W.G. Wyckoff, Crystal Structures, vol. I, John Wiley \& Sons, New York, 1963.

38. I. Petrov, E. Mojab, R.C. Powell, J.C. Creene, L. Hultman and J.E. Sundgren, Appl. Phys. Lett., 1992, 60, 2491-2493.

39. L A Thesing, P Piquini and T Kar, Nanotech., 2006, 17, 1637-1641.

40. M. Zhao, Y. Xia, D. Zhang and L. Mei, Phys. Rev. B, 2003, 68, 235415-4.

41. D. Zhang, R.Q. Zhang, W.M. Chan and K.S. Chan, Diamond and Related Materials, 2004, 13, 425-432.

42. K.P. Huber and G. Herzberg, Molecular Spectra and Molecular Structure, Vol. IV, Constants of Diatomic Molecules, Van Nostrand Reinhold, New York, 1979. 


\section{Figure 1}

a) Side and b) top views of the $\alpha$-alumina (0001) slab model with an Al topmost layer. Each number indicates the corresponding layer for oxygen or aluminum species. Labels a,b, and c are used for equivalent $\mathrm{O}$ atoms. Crosses indicate the position of T1, T2, B and $\mathrm{H}$ sites. The rest of equivalent sites can be generated by cell symmetry.

\section{Figure 2}

Different types of $\mathrm{AlO}_{x}$ coordination: a) $\mathrm{AlO}_{6}$ coordination in bulk, b) $\mathrm{AlO}_{3}$ coordination in relaxed surface, c) $\mathrm{AlO}_{4}$ coordination in $\mathrm{T} 1$ site and d) $\mathrm{AlO}_{4}$ coordination in $\mathrm{T} 2$ site.

\section{Figure 3}

Partial DOS projected onto oxygen adatom and surface aluminum $\left(\mathrm{Al}_{(1)}\right)$ for $\mathrm{T} 1$ minima (singlet and triplet state) over $\alpha$-alumina. O $2 \mathrm{~s}$ and $2 \mathrm{p}$ states and $\mathrm{Al} 3 \mathrm{~s}$ and $3 \mathrm{p}$ states are shown.

\section{Figure 4}

Partial DOS projected onto oxygen adatom, surface aluminum $\left(\mathrm{Al}_{(1)}\right)$ and surface oxygen $\left(\mathrm{O}_{(1)}\right)$ for T2 minima (singlet and triplet state) over $\alpha$-alumina. O $2 \mathrm{~s}$ and $2 \mathrm{p}$ states and $\mathrm{Al} 3 \mathrm{~s}$ and $3 \mathrm{p}$ states are shown.

\section{Figure 5}

Energy profile for all stationary points of oxygen adsorption over $\alpha$-alumina (0001). Singlet (dashed line) and triplet (solid line) energies are depicted. The zero of energy is taken at $\mathrm{O}\left({ }^{3} \mathrm{P}\right)+$ slab asymptote. 
Table 1. DFT and experimental properties of $\alpha$-alumina bulk-terminated (0001) surface

\begin{tabular}{|c|cc|}
\hline & GGA-PW91 & Exp. ${ }^{28}$ \\
\hline $\mathrm{a}=\mathrm{b}(\AA)$ & 4.808 & 4.759 \\
$\mathrm{c}(\AA)$ & 13.117 & 12.991 \\
$\mathrm{~V}_{\mathrm{cell}}\left(\AA^{3}\right)$ & 262.56 & 254.80 \\
$\mathrm{~d}_{\mathrm{Al}(3)-\mathrm{O}(1)}(\AA)$ & 1.990 & 1.972 \\
$\mathrm{~d}_{\mathrm{Al}(3)-\mathrm{O}(2)}(\AA)$ & 1.873 & 1.855 \\
$<\mathrm{O}_{(1 \mathrm{a})} \mathrm{Al}_{(3)} \mathrm{O}_{(1 \mathrm{~b})}\left(^{\circ}\right)^{\mathrm{a})}$ & 79.6 & 79.7 \\
$\left.<\mathrm{O}_{(2 \mathrm{a})} \mathrm{Al}_{(3)} \mathrm{O}_{(2 \mathrm{~b})}{ }^{\circ}\right)$ & 101.2 & 101.1 \\
\hline \hline
\end{tabular}

a) Angles for different choices of the $\mathrm{O}$ atoms ( $\mathrm{a}, \mathrm{b}$ or c) in layers $\mathrm{O}_{(1)}$ or $\mathrm{O}_{(2)}$ are the same 
Table 2. Interlayer relaxations of the top outermost layers of Al-terminated $\alpha$-alumina (0001)

\begin{tabular}{|c|ccccc|}
\hline \hline & GGA-PW91 & GGA $^{23}$ & GGA $^{19}$ & Exp. $^{7}$ & Exp. $^{8}$ \\
\hline$\Delta \mathrm{d}\left(\mathrm{Al}_{(1)}-\mathrm{O}_{(1)}\right)$ & -89.2 & -79.2 & -86 & -51 & -52.8 \\
$\Delta \mathrm{d}\left(\mathrm{O}_{(1)}-\mathrm{Al}_{(2)}\right)$ & 3.9 & 10.3 & 6 & 16 & 1.5 \\
$\Delta \mathrm{d}\left(\mathrm{Al}_{(2)}-\mathrm{Al}_{(3)}\right)$ & -45.5 & -37.6 & -49 & -29 & - \\
$\Delta \mathrm{d}\left(\mathrm{Al}_{(3)}-\mathrm{O}_{(2)}\right)$ & 20.2 & 26.0 & 22 & 20 & - \\
slab size (layers) & 18 b) & 15 & 18 & - & - \\
\hline
\end{tabular}

a) The relaxation of $i$ and $j$ layers is calculated as:

b) The first 10 layers are relaxed. 
Table 3. Calculated GGA-PW91 adsorption energies and geometries for atomic oxygen over the $\alpha$-alumina (0001) eighteen-layer slab model on different sites.

\begin{tabular}{|c|cccccrrr|}
\hline \hline Site & Spin & $\mathrm{E}_{\mathrm{exc}}(\mathrm{eV})^{\mathrm{a})}$ & $\mathrm{E}_{\mathrm{ad}}(\mathrm{eV})$ & $\mathrm{d}\left(\mathrm{O}_{\mathrm{ad}}-\mathrm{Al}_{(1)}\right)(\AA)$ & $\mathrm{d}\left(\mathrm{O}_{\mathrm{ad}}-\mathrm{O}_{(1)}\right)(\AA)^{\mathrm{b})}$ & \multicolumn{3}{c|}{$\left.v\left(\mathrm{~cm}^{-1}\right)^{\mathrm{c}}\right)$} \\
& & & & & \multicolumn{1}{c|}{$\perp$} \\
\hline $\mathrm{T} 1$ & 1 & 0 & 1.82 & 1.802 & 2.872 & 510.9 & 84.8 & 48.5 \\
& 0 & 0.31 & 1.51 & 1.780 & 2.910 & 541.3 & 107.5 & 73.2 \\
$\mathrm{~T} 2$ & 0 & 0 & 2.30 & $1.790 \mathrm{~d})$ & 1.554 & 625.6 & 426.7 & 207.6 \\
& 1 & 1.54 & 0.76 & $1.789 \mathrm{~d})$ & 1.552 & 624.6 & 428.1 & 201.7 \\
$\mathrm{~B}$ & 0 & 0 & 1.45 & 1.786 & 2.458 & 534.8 & 126.0 & $58.1 \mathrm{i}$ \\
& 1 & 0.29 & 0.75 & 1.783 & 1.700 & $551.9 \mathrm{i}$ & 503.1 & 149.1 \\
$\mathrm{H}$ & 1 & 0 & 0.50 & 2.888 & 2.178 & 224.8 & 64.6 & $149.1 \mathrm{i}$ \\
& 0 & 0.01 & 0.49 & 1.854 & 2.197 & 481.0 & 183.3 & $172.5 \mathrm{i}$ \\
\hline \hline
\end{tabular}

a) Excitation energy between the two lowest spin states (i.e., singlet and triplet) of the system

b) The shortest $\mathrm{O}_{a d}-\mathrm{O}_{(1)}$ distance is shown. In T2 site this distance corresponds to $\mathrm{O}_{a d}-\mathrm{O}_{(1 \mathrm{a})}$. Distances to $\mathrm{O}_{(1 \mathrm{~b})}$ or $\mathrm{O}_{(\mathrm{lc})}$ are higher than $3 \AA$.

c) Harmonic vibrational frequencies of the atomic adsorbate with respect to the rigid substrate.

d) The $\mathrm{d}\left(\mathrm{Al}_{(1)^{-}} \mathrm{O}_{(1 \mathrm{a})}\right)$ were $1.833 \AA$ (singlet) and $1.839 \AA$ (triplet). 
Table 4. Calculated GGA-PW91 adsorption energies and geometries for atomic nitrogen over the $\alpha$-alumina (0001) eighteen-layer slab model on different sites.

\begin{tabular}{|c|c|c|c|c|c|c|c|c|}
\hline \multirow[t]{2}{*}{ Site } & \multirow[t]{2}{*}{ Spin } & \multirow[t]{2}{*}{$\mathrm{E}_{\mathrm{exc}}(\mathrm{eV})^{\mathrm{a})}$} & \multirow[t]{2}{*}{$\mathrm{E}_{\mathrm{ad}}(\mathrm{eV})$} & \multirow[t]{2}{*}{$\mathrm{d}\left(\mathrm{N}_{\mathrm{ad}}-\mathrm{Al}_{(1)}\right)(\AA)$} & \multirow{2}{*}{$\left.\mathrm{d}\left(\mathrm{N}_{\mathrm{ad}}-\mathrm{O}_{(1)}\right)(\AA)^{\mathrm{b}}\right)$} & \multicolumn{3}{|c|}{$v\left(\mathrm{~cm}^{-1}\right)^{\mathrm{c})}$} \\
\hline & & & & & & $\perp$ & & $\|$ \\
\hline \multirow[t]{2}{*}{$\mathrm{T} 1$} & $3 / 2$ & 0 & 0.40 & 2.030 & 2.979 & 350.7 & 99.4 & 84.2 \\
\hline & $1 / 2$ & 0.50 & -0.10 & 1.928 & 3.041 & 480.8 & 125.5 & 63.5 \\
\hline \multirow[t]{2}{*}{$\mathrm{T} 2$} & $1 / 2$ & 0 & 1.23 & $1.903^{\text {d) }}$ & 1.501 & 624.3 & 431.0 & 203.6 \\
\hline & $3 / 2$ & 1.53 & -0.30 & $1.906^{\mathrm{d})}$ & 1.489 & 621.4 & 429.1 & 199.6 \\
\hline
\end{tabular}

a) Excitation energy between the two lowest spin states (i.e., doublet and quartet of the system

b) The shortest $\mathrm{N}_{\mathrm{ad}}-\mathrm{O}_{(1)}$ distance is shown. In T2 site this distance corresponds to $\mathrm{N}_{\mathrm{ad}}-\mathrm{O}_{(1 \mathrm{a})}$. Distances to $\mathrm{O}_{(\mathrm{lb})}$ or $\mathrm{O}_{(\mathrm{lc})}$ are higher than $3 \AA$.

c) Harmonic vibrational frequencies of the atomic adsorbate with respect to the rigid substrate.

d) $\mathrm{The} \mathrm{d}\left(\mathrm{Al}_{(1)^{-}} \mathrm{O}_{(1 \mathrm{a})}\right)$ were $1.861 \AA$ (doublet) and $1.869 \AA$ (quartet). 